\title{
A Study on the Vagueness in English Language Teaching from the Pragmatic Perspective
}

\author{
Fang Xi \\ Foreign Language College, Inner Mongolia University of Technology, Huhhot City, China
}

\begin{abstract}
Vagueness, as an intrinsic feature of human language, has caused much attention. Many researches on vagueness have already been done in different fields, namely in daily conversations, newspapers, advertisements, science, literature, business affairs, and the like. However, up to now, most researches on vagueness have been confined to the semantic field, while the pragmatic perspective had not been paid much attention to yet. Besides, so far, much effort has been made on the theoretical study of language vagueness, but less on that in different aspects of English Language Teaching. Since vagueness plays a very important role in English language teaching, a research on this topic is necessary and essential. Based on the theories of pragmatic vagueness, this paper attempts to analyze the pragmatic function of vagueness, various language vagueness phenomena existing in the whole process of English language teaching and its functions. Then some possible suggestions for vague language teaching are proposed, namely, teaching with reference to Chinese, practice based on text, and a thorough understanding of English culture. It is hoped that it is beneficial to English language teaching.
\end{abstract}

Index Terms - vagueness, pragmatic function, implication, suggestion

\section{INTRODUCTION}

It is impossible and unnecessary for language, an indispensable component of our daily life, to be clear and precise all along, in communicative activity in particular. We need and we often use vagueness in thinking and communication, yet we may not be aware of the fact that the language we are employing is fuzzy. As vagueness is an intrinsic feature of human language, many researches on vagueness have already been done in different fields, namely, in daily conversations, newspapers, advertisements, science, literature, business affairs, press conferences, and the like. However, up to now, most researches on vagueness have been confined to the semantic field, while the pragmatic perspective has not been paid much attention to yet. Besides, so far more effort has been made on the theoretical study of language vagueness, but less on that in different aspects of English Language Teaching. Accordingly, based on the theories of pragmatic vagueness, this paper attempts to analyze various language vagueness phenomenon existing in the whole process of English language teaching, put forward the idea of employing vague language in teaching environment, and raise the teachers and students' awareness of vagueness in human language.

\section{LITERATURE REVIEW}

\section{A. Research on Vagueness Abroad}

The study of vagueness in language has a long history. It could be originated from the study of philosophy, as philosophy is the origin and essence of other disciplines. The research on vagueness in philosophy can be traced back to ancient period. Eubulides, a Greek logician and Philosopher, might have been the first person to introduce the concept of vagueness into the study of philosophy. At the end of the nineteenth century, there were three Philosophers: Gottlob Frege, Charles Sanders Peirce and Berrand Russell, whose researches inspired people's great interest in the study of vagueness.

In 1937, Max Black published his Paper Vagueness: An Exercise in Logic Analysis. This paper can be taken as a kind of transition, and it has transferred the philosophic attention on vagueness to human language. Since then, vagueness has acquired a more positive image. On the other hand, one of Black's leading ideas is that vagueness could be measured in an experimental way, which later becomes the foundation of the fuzzy sets theory of Zadeh from the perspective of philosophy.

Professor Rosch and Williamson from University of Edinburgh studied vagueness from the cognitive perspective. Rosch found out that categorization played an essential role as a typical model in fuzzy set and thus exerting great influence on semantic category. In his book Vagueness, Williamson proposed metalanguage vagueness and argued that "People's knowledge was so limited that it couldn't explain the meaning of vagueness in metalanguage (Zhang, 2005)."

In 1965, the American scientist L.A. Zadeh proposed the "fuzzy set theory", which successfully broke through the previous concept of "two-valued logic". Zadeh pointed out that not only objects in the real world but also languages and thought of human beings are always lack of sharply defined boundaries. His theory about vagueness made vagueness become a study of science and has influenced a lot of studies in other fields. Edified by Zadeh's vagueness theory, 
American linguist G. Lakoff introduced "fuzzy set theory" into natural language, and he also proposed the concept of ranking from "degree of membership" into "true value" (Lakoff, 1973). McCawley also made great contribution to this research, as he further emphasized the true value of ranking and thus made a more elaborate research on vagueness (McCawley, 1981).

In 2000, Australian linguist Burns tried to study human language and vagueness in human being's concept from the pragmatic perspective. She did researches on how Sorites Paradox resulted in philosophers' confusion, and also made comments on the theories, trying to provide solutions to the problems. She believed that people could figure out some principles of the language vagueness, which gave some directions to the study of vagueness in the pragmatic perspective.

Nowadays, pragmatics has attracted many scholars and linguists' attention, thus tends to become a basically independent discipline. Joanna Channell described the pragmatic functions of vague language in detailed information. She holds the opinion that "understanding vagueness requires hearers to bear not just knowledge of the lexis and grammar of English, but also pragmatic knowledge about how language is used, and how it relates to its settings (Channell, 2000).

In conclusion, the above researches are mainly made by linguists abroad in different fields, from which it is found that their researches mainly focus on the meaning of language vagueness. To be specific, they did researches on vagueness respectively from the view of philosophy, semantics, psychology, cognition and pragmatics, and accordingly promoted prosperous development of language vagueness.

\section{B. Research on Vagueness in China}

The first linguist to study vagueness in China is Professor Wu Tieping, who introduced Zadeh's fuzzy set theory into China in 1975. Since then, Chinese scholars began to show great interest in language vagueness. Wu Tieping pointed out that vagueness is a quite common language phenomenon and he made a very careful study on vague words, such as the vagueness of words for time, color and gender, etc, which has laid a solid foundation for further researches on vagueness.

In the 1990s, Wang Rongpei translated some sections of J. Tylor's Linguistic Categorization and S.L. Tsohatzidis' Meanings and Properties into Chinese, making linguists in China begin to know the current trend of combination of vague linguistics and cognitive linguistics abroad. Zhang Qiao in Vague Semantics also illustrates the academic trend of vague language in overseas countries (Zhang, 1998). Later, Shi Anshi and other scholars have made a detailed study of vague semantics.

He Ziran, Yang Xianyu, Li Zuowen, etc, have discussed the pragmatic functions of language vagueness in daily communication. Yet all these studies are merely limited to vague words, vague sentences, vagueness in discourses or its pragmatic meanings, and pragmatic functions of vague language are seldom touched.

In recent years, many scholars like Chen Yide (2001), Xia Yun (2001), Xiao Yunshu (2001), Yu Jianshu (2000) and $\mathrm{Ma} \mathrm{Li} \mathrm{(2003)} \mathrm{have} \mathrm{tried} \mathrm{to} \mathrm{study} \mathrm{vagueness} \mathrm{from} \mathrm{a} \mathrm{stylistic} \mathrm{point} \mathrm{of} \mathrm{view,} \mathrm{for} \mathrm{example,} \mathrm{vague} \mathrm{rhetoric} \mathrm{in} \mathrm{poems,}$ application and translation of vague language in law documents, diplomacy, advertisements, literature works, etc.

With the rapid development of applied linguistics, vagueness has drawn people's great attention in English Language Teaching. However, the previous studies merely focus on the vague meaning of words which appeared in the comprehension texts or passages. According to their researches, teachers only mention the surface of vague phrases or expressions in English language teaching, while the use of vague language in communication has been ignored. As a result, teachers, on the whole, fail to arouse students' interest in using vague language.

In fact, the study of pragmatic functions of vague language comprises the effects of using vague expressions and the goals the speakers intend to achieve, both of which must be solved in English Language teaching, because its purpose is to improve the students' communicative competence. Accordingly, the present study of vagueness in English Language Teaching is a new trial and a significant one.

\section{Pragmatic Functions of Vague Language}

In classroom communication, teachers and students frequently use vague language, because it has specific pragmatic functions: creating a mild tone, filling lexical gaps, giving the right amount of information, withholding information deliberately. The proper use of vague language is an important strategy for effective classroom communication.

\section{A. Creating a Mild Tone}

In classroom communication, the teachers and students often use vague language to create a mild tone in their speeches in order to be polite and maintain good atmosphere and facilitate the teaching process. It is an important function of vague language, because it can make the utterance more objective and euphemistic. The teachers and students often add plausibility vague language like I think, seem to, may, possible to their speech to weaken the tone of affirmation. The following statement by a teacher may serve as an example.

Teacher: Last time, when I mentioned this word, I saw some students were talking to each other. I think that possibly some students may not know much about this word. Here I would like to emphasize it again...The teacher uses "I think" and "possibly" to make the utterance less assertive and lessen the force of their expression. 


\section{B. $\quad$ Filling Lexical Gaps}

Sometimes, in classroom communication, teachers or students may not come up with the very word they want to say. That is to say, teachers and students do not know that word or they just forget it. The following utterance of a student may serve as an example.

Student: He is...er...kind of doctor who takes care of people's mental health.

It occurs to us that the student wants to say the word "psychologist". However, either because she does not remember this word, or because she never knows this word anyhow, she uses kind of doctor as a substitute.

In classroom communicative activity, an important function of vague language is to fill the lexical gaps. In the process of learning a foreign language, the application of vague language can assist the learners to say words or convey ideas of which they do not know or precise information is not required. Besides, in this way communication can go smoother and embarrassment avoided.

\section{Giving the Right Amount of Information}

Grice noticed that speakers appear to tailor their contributions in particular ways, and he pointed out that vague language is just the kind of device which speakers employ to tailor their conversation. For example:

- Oh, what a beautiful dress. How much does it cost, Mary?

- It cost five hundred pound or so.

- It is a good buy.

The approximate number is more often used because it doesn't convey more information than if you knew the exact figure. In this example, even if they knew it cost five hundred and thirty-nine, it won't get them any further.

\section{Withholding Information Deliberately}

Sometimes, when speaker do not have the intention to offer accurate information, they may resort to vague terms on purpose in order to solve the problem. The utterance of a woman might be a typical example: "I am about 28 years old." The woman seems to withhold her exact age. When questioned, she deliberately chose the figure 28 and added a vague word "about" before it. Since in some cultural tradition, women are kind of sensitive when they are about or a little over thirty.

\section{The Analysis of Vagueness in English Language Teaching}

This part focuses on analyzing various vagueness phenomena existing in the whole process of ELT. The teaching process mainly includes English pronunciation, vocabulary, discourse, etc, aiming to raise both the teachers and students' awareness of using vague language.

\section{A. Vagueness in Evaluation}

Vagueness in evaluation generally means that teachers should try to use vague expressions to evaluate the students. For example, when talking about a student who is not good at learning, a teacher should say "He/she is working at his/her own level." instead of saying "He/she is a below-average student". When speaking of a student who is not so clever, a teacher should say "He/she can do better with help" instead of saying "He is stupid or a slow learner."

In this way, vague words will be more flexible, and much easier to be accepted by students. And also they will be helpful to protect the students' self-esteem and finally to enhance their self-confidence.

\section{B. Vagueness in Pronunciation}

It is known to us that in English there are altogether twelve single vowels. And these twelve single vowels are spoken out from approximate positions of people's organs. However, drawing a clear-cut borderline between the vowels near to each other proves not to be easy. These vowels are vague because of the simple fact that they are decided by high, low, front or back tongue position and also round degree of lips. As a result, it is hard to classify them into different groups. Besides, there is still no clear borderline between vowels and consonants. For instance, [w] and [j] are called semivowels or glides, which possess both the features of vowels and consonants. So whether they belong to vowels or consonants is still vague.

\section{Vagueness in Lexics}

Vagueness in lexics is very common. There are plenty of vague expressions in English vocabularies. For example, vague words expressing time include spring, summer, autumn, winter; in the morning, in the afternoon, in the evening; a few days ago, a few days later; sooner or later; in recent years, in the past few years, etc.

Vague words expressing amount include a large number of, a large amount of, a great many, hundreds of, thousands of, a little, a few, etc. Vague words expressing age comprises the childhood, the juvenile, the young, the middle-aged, the aged, etc.

There are also many pronouns and adverbs denoting vague meanings, such as some, someone, something, anyone, anything, somewhat, somewhere, somehow, about, just, around, kind of, sort of, possibly, probably, perhaps, almost, nearly, that depends, I'm afraid, generally speaking, so to speak, etc.

From the above vague words or expressions, it is obvious that vagueness is a common phenomenon in English lexics, 
thus we should pay special attention to the vague expressions and try to employ them flexibly in communication.

\section{Vagueness in Grammar}

Concerning vagueness in Grammar, the present tense is typical. Here is an example: this plane takes off at eight o'clock and gets to Beijing airport at ten o'clock.

This sentence has two different senses: one refers to the habitual action that often occurs, stressing time and repeatability; the other refers to the action that will surely happen in the future. Therefore, we may notice that in the above sentence vagueness occurs because of the different borderlines of the time in present tense.

Accordingly, in grammar teaching, teachers should attach importance to its vagueness, so that students will get a comparatively clearer understanding.

\section{E. Vagueness in Discourse}

In this section, discourse consists of both text books and literature works.

For the text books, this paper chooses some typical vague expressions from Advanced English (Book1 \& Book11) according to different text styles.

1. Vagueness in Exposition

Middle Eastern bazaar takes you back hundreds - even thousands - of years.

(Zhang \& Wang, 1999, P1. The Middle Eastern Bazaar)

In this sentence, it is not necessary for the vague expression "hundreds - even thousands - of years" to be of exact number, because as readers enters the Middle Eastern Bazaar with the author's depiction, they find the bricks and stones aged, the architecture ancient, and a handicraft economy thriving. However, the author only used one sentence expressing so many details, which shows one of the pragmatic functions of vague language, i.e., to give the right amount of information. Suppose the author described the Middle Eastern Bazaar in a more detailed way, it would break the maxim of quantity. Here it should be noticed that vague language is very useful in expository texts. When teaching this part, if the teacher could introduce some basic pragmatic knowledge, such as vague language and maxim of quantity even cooperative principle, it will be easier for the students to study pragmatics in the future. And meanwhile, they will be more interested in linguistics, which in return will reduce the teacher's task when teaching linguistics.

2. Vagueness in Narration

A wave of cigar smoke accompanied Ogilvie in. When he had followed her to the living room, the Duchess looked pointedly at the half-burned cigar in the fat man's mouth, "My husband and I find strong smoke offensive. Would you kindly put them out." (Zhang \& Wang, 1999, P 91. Blackmail)

Normally, the Duchess' last sentence "Would you kindly put them out" should end with a question mark instead of a full stop. This falling tone shows that the Duchess is forcing the detective Ogilvie to stop smoking. Pragmatically speaking, the sentence "Would you kindly put them out" is a vague expression. The speaker, the Duchess used passive politeness strategy to save the hearer Ogilvie's passive face. In fact, the Duchess didn't welcome Ogilvie at all. This sentence shows that the speaker's vague expressions are properly used to achieve power and politeness.

When learning this part, teachers could first introduce the pragmatic function of vague language, its power and politeness, to the students. And after that, some other pragmatic functions of vague language in narration (mainly in conversation) could also be explained to the students. With a good understanding and mastery of pragmatic functions of vague language, the students will be likely to find and analyze some other vague expressions in the text by themselves.

3. Vagueness in Prose

The Colonel, who is not too offensively an Empire-builder, sometimes tries to talk to me about public affairs; he says he used to read me, and is rather charmingly deferential, prefacing his remarks "Of course it's not for me to suggest to you..." and then proceeding to tell me exactly how he thinks some topical item of our domestic or foreign policy should be handled $\mathrm{He}$ is by no means stupid or ill-informed: a little opinionated perhaps, and just about as far to the Right as anybody could go, but I like him, and try not to tease him by putting forward views which would only bring a puzzle look to his face. Besides I do not want to become involved in discussion. I observe with amusement how totally the concerns of the world, which once absorbed me to the exclusion of all else except an occasional relaxation with poetry or music, have lost interest for me even to the extent of a bred distaste. (Zhang \& Wang, 1999, P 289. No Signposts in the Sea)

In the above paragraph, a lot of English hedges, which are the core of vague language, have been employed. To be more specific, "by no means", "a little", "just", "anybody" are alterable hedges, which clearly show the degree and scope of the description. The author uses these alterable hedges to describe the characteristics of the Colonel, so as to give the readers a more objective impression of the Colonel.

Besides, some mitigating hedges such as "Of course", "Perhaps" help to make a direct guess or evaluation of the Colonel, so as to help the readers get more familiar with him.

4. Vagueness in Public Speeches

The main characteristic of public speeches lies in its appeal and implicitness, which are achieved by the speakers' vague thinking pattern. In their speeches, the speakers usually use vague language intentionally to set up certain artistic conception to express strong emotion, which cannot be achieved by using exact description. Let's take the inaugural address given by President Kennedy as an example: 
To our sister republics south of our border, we offer a special pledge: to convert our good words into good deeds, in a new alliance for progress, to assist free men and free governments in casting off the chains of poverty.

In the above sentence, Kennedy chose the ordinary word "sister" from thousands of English vocabularies. Of course he intended to express his implied meaning. As is known to all, America has already been a powerfuland dominant country in the world at that time. And many small undeveloped counties were afraid of America and intended to be "loved" by America. Kennedy was quite clear about that, so he used the word "sister", to modify "republics". In this way, he did not only cover America's ambition of dominating the whole world but also left a good impression to those small undeveloped countries. The word "special" also has a vague and implied meaning. Seen from the surface, American government was quite generous and willing to offer help. As a matter of fact, it shows that America always regards itself as No. 1, and thus merely considers its invasion and deprivation of those small countries as a special policy. Here we may notice that Kennedy is a very careful and smart speaker, who is good at the choice of vague words.

5. Vagueness in Literature

In literary works, if vague language can be used properly, they would certainly have some aesthetic values, which will be missed if there is not any vague language at all. Sometimes, too much exactness or precision would change or even destroy the beautiful values of literature works. The famous Chinese linguist Wu Tieping holds that there will be no literary works at all without vague language, and this is believed to be the key and essence of modern literary works.

For many years, love has been a topic explored by millions of writers or poets. However, it is not easy for them to give an exact definition of love. It is obvious that it should not be touched upon directly and mechanically, for that will destroy the beauty of poems. For instance, in William Shakespeare's Sonnet18, the poet compared his lover to a summer's day as well as the sun in the eye of heaven. By employing some other vague expressions, such as "more temperate" more lovely, etc. William Shakespeare has vividly described the inner feeling of a man who admired and cherished love for his beautiful girl. Therefore, by using vague expressions and necessary similes or metaphors, the poet has successfully portrayed a vivid and lovely figure to his readers.

To sum up, the above section analyzes the functions of vague language both in text books and literary works for English majors. From the above analysis, we may find that vague language is not only widely used in spoken language such as in daily communications, but also in written language such as in the literary works.

\section{IMPLiCATIONS OF VAGUENESS IN ENGLISH LANGUAGE TEACHING}

We know that vague language is very common both in text books and literary works from the last part, now the present paper is to probe into its pragmatic functions in real teaching environment and to find out how it benefit teachers and students. In teaching practices, teachers and students may face with various unpredictable circumstances where vagueness may come to our rescue. To a certain extent, the adoption of vague language may sometimes work out wonders for them.

\section{A. Benefiting Students}

1. Appreciating the Beauty of Vagueness

The use of vague language can not only achieve aesthetic effect, but also develop student' imagination. The well-known monologue in Shakespeare's famous play Hamlet may serve as a convincing example:

"To be, or not to be - that is a question."

Owing to their different experiences, characters and insights, students' perception of Hamlet may vary. In other words, people hold different versions of Hamlet in their mind. In their teaching practice, what teachers should do is that they should nurture students' ability in appreciating language beauty.

Besides, some rhetoric effects can be achieved through the use of vague language. Let's take the following two sentences as examples:

a. The enemy soldiers were scared like anything.

b. He is ten times the man you are.

Sentence a achieves the effect of exaggeration, and sentence b gains the effect of emphasis. Students, under the guidance of their teachers, should acquire the use of vague language so that they can speak and write more effectively, even humorously.

2. Achieving a Better Understanding of Culture

In their learning of a foreign language, students may attach great importance to speech sounds, intonation, vocabulary, grammar, etc. They may neglect differences between their native and foreign cultural traditions. It has been acknowledged that spoken words or written words convey only part of the meaning, and the remaining part is conveyed either through conversational implicature or culture background. Therefore, teachers should remind their students of the employment of vague language whenever it is possible.

3. Saving Face

In classroom activity, students make errors all the time, instead of criticizing them point-blank, teachers may choose some fuzzy terms to alleviate their judging utterance. The following utterance of a teacher may give us some enlightenment.

These days, I found most of the students behave well in the composition assignment, yet some of you did not pay 
much attention to what I have told you in class, and their compositions leave a lot to be improved.

In this utterance, "these days", "most", "behave well", "some", "much" and "a lot" are resorted to in demonstrating the problems of the students, thus students' faces are saved. In other words, such utterances as "most of the students behaved well in this dictation, only some of you leave a lot to be desired" and "I would suggest that you practice more after class" are all very useful for teachers to save students faces.

\section{B. Benefiting Teachers}

1. Creating a Comfortable Atmosphere

When asking questions, teachers may resort to some demonstrative pronouns to allay the students' nervousness and stimulate their participation. For instance, teachers may habitually say "Any volunteers?" Owing to the reserved character of the Chinese students, they tend to act passively in class, and they seldom speak out their minds aloud in public. Through the employment of vague terms, students are entitled with the right to choose to participate or not. Teachers create a comfortable classroom atmosphere tactically.

2. Comforting the Students

When teachers give students assignment, vague language are frequently used to reduce the difficulty, which could, to some degree, lessen students' rejecting mood so that it could arouse students' interest in finishing the assignments willingly instead of reluctantly. Teacher may use "I am afraid, I think, I would, etc." in their evaluation of the students' classroom activities or in their assessment of students' homework. The following remarks may be of value, "I think you may sum up the main idea in this way...", "I would suggest you practice more after class", "if you speak a bit louder, it would be much better". Suggestions like that would be more agreeable and acceptable to the students. Thus, teaching objectives are more likely to be achieved.

3. Coping with Abruptness

Though teachers make careful plans for every task beforehand, a certain unexpected changes are bound to happen in actual teaching practice. Consequently, the allocated time for each task needs proper adjustment. Under this circumstance, such fuzzy terms as "about", "approximately", "at least”, "at most”, "or so", "under”, "over”, etc. could be used. Let's take the following instruction of a teacher as an example:

Now class, I wi11 give you about 5 minutes to discuss this topic. And then I wi11 ask 2 or 3 of you to present their ideas. As there are 50 students or so in our class, I would divide you into 13 groups, about 4 in each group.

By using these vague terms, this teacher carried out his classroom activity more effectively and flexibly.

4. Avoiding Awkwardness

In actual teaching practice, teachers at times may fail to come up with the very word or expression they wish to use. In this case, they may turn to vague terms as a way out. A teacher, for instance, gave the following statement when she forgot a word, "When it is on fire, people usually use, umm...er...kind of tool which contains dry ice and is often seen in the wall in public place to put out fire." We realize the word this teacher wanted to say is "fire-extinguisher". This teacher forgets the exact word for "fire-extinguisher"; with the help of his explanation, some top students may speak out the right word "fire-extinguisher". Thus, the teacher saves his own face.

To sum up, teachers should develop students' awareness of the vague property of language; effective use of it can benefit them greatly.

\section{Possible Suggestions for Teaching Vague Language}

\section{Teaching Vague Language with Reference to Chinese}

As a Chinese student, Chinese will more or less interfere with the study of a foreign language. Chinese will certainly influence the learning process. The learner will resort to Chinese when they have difficulty in expressing their idea or understanding something. In this circumstance, we can make full use of Chinese in the learning process. That is to say, we can learn the use of vague language through Chinese. Speakers can understand the pragmatic rules of their own language and know what is proper and what is improper in the communication. This can be applied to both Chinese and a foreign language. The same phenomenon exists in the two languages. On the one hand, learning vague language is a part of pragmatic competence. In Chinese, hedges like “大概”, “有点”, “稍微”, “很”, “我认为”, “可能”, “据说”.... are used very frequently. Teachers should make the students aware that the use of vagueness is important and necessary in expressing certain meanings. Sometimes the use of vagueness is more proper than the exact expression. And this applies to Chinese as well as English. On the other hand, Chinese is much different from English. Sometimes a speech considered polite and proper in Chinese might not be so in English. Therefore, when teaching students, teachers should make a comparison of the vague language in English and Chinese. In this way, students distinguish the difference and make full use of the similarities between English and Chinese. In this way, students may have a better command of vague language.

2. Practice Based on the Text

In order to use a foreign language appropriately and politely, learners should know a lot about the vague language and how to use them to express their ideas successfully. After that, the students should make a lot of practice. Practice based on the text fragments is one way to make better use of vague language. Teachers could make good use of the vague language in the text and explain the usage and functions in detail, and help the students use vague language properly in communication. Some steps are as follows: students are required to find out the vague items used in the text 
and classify them according to the pragmatic classification. Then they are asked to discuss the pragmatic functions of the items. Finally, they are required to remove all the vague items in the text and see what effect will be achieved without the use of those items.

3. Teaching Vague Language by Introduction of Culture

Language and culture are closely related with each other. When we study a language, we should take the culture into consideration. It is the same case with the study of vagueness. What is appropriate in one culture may not be appropriate in another culture, so teachers should give due weight to culture when teaching the proper use of vagueness.

There are a lot of differences between English and Chinese culture, and it is reflected in the two languages. Sometimes, students may not make any grammatical mistakes when they say something, but their speech may be inappropriate or they may not be able to be understood by others. In the process of teaching or learning a language, we should have a thorough understanding of different cultures to ensure the successful communication. Teachers may present the students with a full picture of the English culture. When they communicate with others, they are more likely to choose the proper way of talking.

\section{SUMMARY}

Vague language is very common in English learning and plays an important role in English language teaching. A study of vague language from the pragmatic perspective is something novel, and it may be beneficial to English Language Teaching, for a good command of some pragmatic functions of vague language and a full awareness of using vague language will not only facilitate teachers' teaching practice but also improve students' communicative competence as well. Through analyzing the pragmatic function of vagueness, various language vagueness phenomena existing in the whole process of English language teaching and its functions, the present paper comes up with some suggestions for the teaching of vague language. It is hoped that it may be beneficial to English language teaching.

\section{REFERENCES}

[1] Black, M. (1937). Vagueness: An Exercise in Logic Analysis. Philosophy of Science, 4, 427-455.

[2] Burns, L C. (2000). Vagueness Language. Shanghai: Shanghai Foreign Language Teaching Press.

[3] Channell Joanna (1992). Vague Language. Shanghai: Shanghai Foreign Language Education Press.

[4] Chen Yide. (2001). On fussy rhetoric and its pragmatic functions. Journal of Tianjin Foreign Studies University, 2, 27-30.

[5] Gao, Y. X. (2006). A Study of Vagueness in English Language Teaching from the Perspective of Pragmatic Function. (MA thesis). Northwestern University, XiAn.

[6] Gan, L. (2010). On vague linguistics and college English teaching. Journal of Kaili University, 28(2), 76-78.

[7] He, Z. R. (1985). Hedges and verbal communication. Foreign Language, 5, 27-31.

[8] He, Z. R. (2004). Contemporary Pragmatics. Beijing: Foreign Languages Teaching and Research Press.

[9] Lakoff, G. (1973). Hedges: A Study in meaning criteria and the logic of fuzzy concepts. Journal of Philosophical Logic, 4, 458-508.

[10] Li, Z. W. (2001). On the interpersonal function of hedges. Journal of Tianjin Foreign Studies University, 3, 1-3.

[11] McCaley, J. D. (1981). Everything that Linguists Have Always Wanted to know about Logic. Oxford: Basil Blackwell.

[12] Wu, T. P. (1999). Fussy Linguistics. Shanghai: Shanghai Foreign Languages Education Press.

[13] Yang, X. Y. \& Peng, J. Y. (2001). On the stylistic function of vague language in daily conversation. Journal of Tianjin Foreign Studies University, 8(2), 31-33.

[14] Yu, J. S. (2000). Fuzzy language applied in English journalism. Journal of Shanghai University, 7(2), 92-97.

[15] Zadeh, L.A. (1975). Introduction to the Theory of Subsets. New York: Academic Press.

[16] Zhang, H. X. \& Wang, L. L. (Eds.) (1999). Advanced English. (2vols). Beijing: Foreign Language Teaching and Research Press.

[17] Zhang, M. \& Zhu, X. M. (2005). A survey of contemporary fuzzy linguistics research in the West. Contemporary Linguistics, 3 , 259-267.

[18] Zhang, Q. (1998). Fussy Semantics. Beijing: Chinese Social Science Publishing House.

[19] Zhang, X. (2010). On the Use of Vague Language in English-Language Teachers' Talk - An Empirical Study. (MA thesis). TaiYuan University of Technology, Taiyuan.

Fang Xi was born in Bayannur, China in 1984. She received her MA degree in linguistics from Inner Mongolia University, China in 2008.

She is currently a lecturer in the Foreign Language College, Inner Mongolia University of Technology, Huhhot, China. Her research interests include pragmatics, sociolinguistics and pedagogy. 